\title{
Correction to: Single Helix Screw Pile Behavior Under Compressive Loading/Unloading Cycles in Dense Sand
}

\author{
Adnan Anwar Malik (D) Jiro Kuwano
}

Published online: 26 June 2020

(C) Springer Nature Switzerland AG 2020

\section{Correction to:}

Geotech Geol Eng

https://doi.org/10.1007/s10706-020-01385-4

In the original publication of the article, the coefficient of determination $\left(\mathrm{R}^{2}\right)$ was mistakenly written as "0.99" in Figure 6a. The actual value of coefficient of determination $\left(\mathrm{R}^{2}\right)$ is " 0.81 ".

The corrected Fig. 6a is provided below.

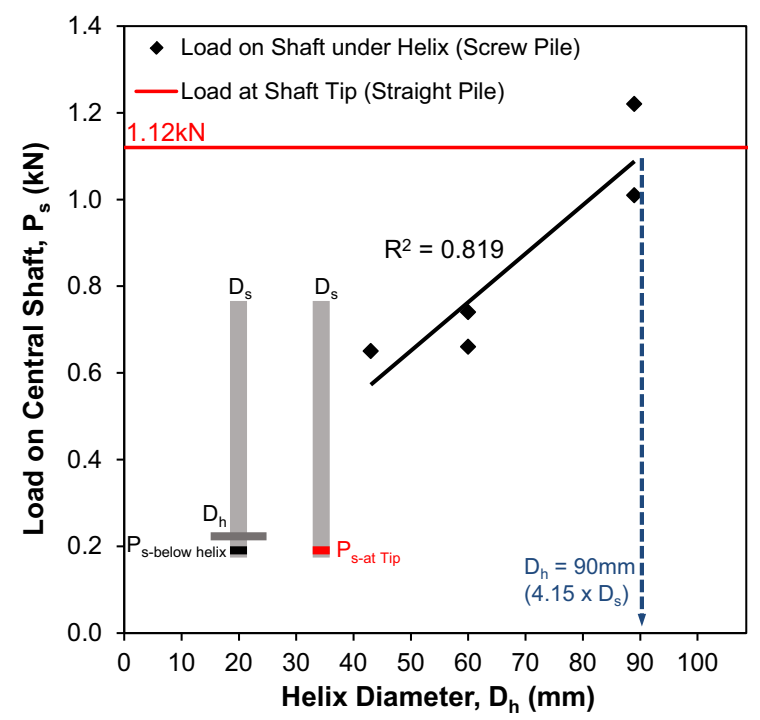

Fig. 6 Load distribution under the helix with increasing helix diameter a comparison of load on central shaft under helix with straight pile tip load

Publisher's Note Springer Nature remains neutral with regard to jurisdictional claims in published maps and institutional affiliations. 